"The History of Plant Propagation in England". The third was by Mr. G. E. Fussell, on "The Grasses and Grassland Cultivation, 1500-1900".

All three papers were devoted to some aspect of the history of farming technique, and this is in accordance with the policy of the Society. At the annual conference normally held at the end of April, papers on local history or on some aspect of economic or social history are presented. If local, the lecturers usually try to deal with the neighbourhood in which the conference is held. At the winter conference in December, papers on technical history are read. Papers read at the conferences are not necessarily printed in the Agricultural History Review, which is published by the Society and distributed free to members. It appears twice a year and includes notes, original papers and book reviews. It can also be purchased by non-members. The honorary secretary, Mr. J. W. Y. Higgs, Museum of English Rural Life, 7 Shinfield Road, Reading, will welcome inquiries from anyone interested.

\section{Toxic Hazards of Pesticides to Man}

THE development of strains of insects which are resistant to the usual pesticides may make it necessary to change over to the use of more dangerous substances, for example, in the control of malaria. This is one reason why it is important that the study of the toxicity of modern pesticides and of the precautions necessary in handling them should be actively pursued. A study group set up by the World Health Organization under the chairmanship of Dr. J. M. Barnes (Serum Research Institute, Carshalton, Surrey) has just summarized its findings (World Health Organization: Technical Report Series 1956, No. 114 ; pp. 5l. H.M.S.O ; $3 s .6 d$. ). The report contains useful information on the pesticides containing chlorine and phosphorus and on their toxicity to man and the higher animals, and makes suggestions for safeguards in their use, both indoors and outdoors. Further lines of investigation are suggested. Blood cholinesterase estimation is the most reliable test of harmful exposure to the organophosphorus insecticides, such as parathion. An appendix gives the names of the institutions and their individual workers in the different countries where problems of insecticide toxicity towards vertebrates are being studied. Information is included on the compounds being investigated and the general types of work being done in the different centres.

\section{Amino-acid Metabolism in Detached Leaves}

C. D. Nelson and G. Krotkov (Canad. J. Bot., 34, 4,423 ; 1956) have investigated the metabolism of carbon-14 amino-acids and amides in detached leaves of the broad bean. Leaves were placed with their petioles in $0.01 M$ ammonium nitrate and allowed to carry on photosynthesis in carbon-14 dioxide for various periods from 12 to $125 \mathrm{~min}$. The radioactivities of the various amino-acids were degraded by decarboxylation with ninhydrin. From the specific activity data it was concluded that the amino-acid closest to the site of carbon dioxide fixation in photosynthesis was alanine, followed by aspartic and glutamic acids, with the amides farthest removed. From the intramolecular distribution of label it was concluded that asparagine and glutamine were formed from their corresponding amino-acids. The labelling in aspartic and glutamic acids was not consistent with the view that these two amino-acids are formed from their corresponding $\alpha$-keto acids produced by operation of the conventional tricarboxylic acid cycle. A $\mathrm{C}_{2}$ plus $\mathrm{C}_{2}$ condensation is postulated for the formation of aspartic acid. A shift in the double bond in the aconitase reaction of the tricarboxylic acid cycle would account for the observed labelling in glutamic acid. When acetate1-carbon-14 was fed to detached broad bean leaves in the light or dark, the distribution of label in glutamic acid supported the suggestion that there is such a shift in the double bond in the aconitase reaction. Sodium arsenite, infiltrated into tobacco leaves, inhibited the biosynthesis of asparagine but not that of glutamine.

\section{Proceedings of the Fifth Colloquium Ampère}

The texts of the twenty-four contributions to the Fifth Colloquium Ampère, held in Geneva during March 21-23, are printed in a special number of Vol. 9 of the Archives des Sciences. Nine different countries are represented. Most of the contributions are brief, being only one or two pages in length, and the main topies of discussion are the properties of dielectrics at high frequencies, ferrites, and paramagnetic and nuclear resonance. Review articles are contributed by C. J. Gorter (Kamerlingh Onnes Laboratory, Leyden) on investigations on magnetic resonances during the past twenty years in the Netherlands; L. Guilotto (University of Pavia) on recent work on the time of nuclear relaxation performed at Pavia; A. Lösche (Physikalische Institut, Leipzig) on work on paramagnetic nuclear resonance at Leipzig; P. Grivet (University of Paris) on the development of nuclear resonance in France and on recent progress in experimental methods in the United States; and C. H. Townes (Ecole Normale Supérieure, Paris) on recent developments regarding the measurement of time. The contributions are all in French, and no abstracts are provided.

\section{Functions of the Natural History Museum}

Sir Gavin DE BEER, director of the British Museum (Natural History), has served a useful purpose by preparing some observations on the functions of natural history museums in general and of the Natural History Museum in particular. It was appropriate that it should appear during "Museums Week" (October 7-13), which was sponsored by the International Council of Museums. Sir Grvin describes the purpose and object of natural history museums and then details their educational function. Stress is laid on the importance of scientific research in natural history museums and the claim is justly made that they are indispensable instruments of modern civilization and human welfare. Apparently this exceedingly useful paper is not a publication in the usual sense of the term, but no doubt copies can be obtained from the British Museum (Natural History) by those interested.

\section{Textile Institute Award for Technical Teachers}

The Textile Institute has decided to make a special award of a medal and $£ 20$, which, by arrangement with the City and Guilds of London Institute, is offered in that organization's Technical Teachers' Certificate examination to the most successful candidate who is a part-time teacher of textiles. The first recipient is Mr. Robert Noel Ward, of Liverpool, a research chemist with British Enka, Ltd., and part-time lecturer in the manufacture of rayon and 